\title{
Regulating self-organized collaborative learning: the importance of homogeneous problem perception, immediacy and intensity of strategy use
}

\author{
Nadine Melzner ${ }^{1}$ (D) $\cdot$ Martin Greisel $^{2} \cdot$ Markus Dresel $^{2} \cdot$ Ingo Kollar $^{2}$
}

Received: 13 December 2019 / Accepted: 25 June 2020 / Published online: 1 July 2020

(C) International Society of the Learning Sciences, Inc. 2020

\begin{abstract}
Very often, university students deliberately form self-organized study groups, e.g. to study collaboratively for an upcoming exam. Yet, very little is known about what regulation problems such self-organized study groups encounter during their learning process and how they try to cope with these problems. Therefore, this study investigates how completely self-organized groups (i.e., non-guided groups outside the classroom that form without external impulse) regulate their collaborative learning process when faced with different kinds of regulation problems. More specifically, we tested the hypotheses that members of self-organized study groups are more satisfied with their group learning experience (a) the more homogeneous their problem perceptions are within their group, (b) the more they apply immediate (rather than non-immediate) strategies to remedy their regulation problems, and (c) the more frequently they apply regulation strategies. In a longitudinal study, $N=122$ students, voluntarily studying for their exams in $N=52$ groups, were asked to indicate the types of problems they experienced, the types of strategies they used to tackle those problems, and their satisfaction with their group learning experience after each of their self-organized study meetings. Hierarchical linear modeling confirmed all hypotheses. Qualitative analysis of two selected groups' selfreported situational data provided additional insights about the mechanisms that may have contributed to the results. Our study provides important directions for future research, including the recommendation to identify the processes by which groups (a) can reach homogeneity of problem perceptions and (b) coordinate the choice of appropriate strategies within the group.
\end{abstract}

Keywords Collaborative learning · Homogeneous problem perception · Immediacy of strategy use $\cdot$ Intensity of strategy use $\cdot$ Self-organized study groups

Nadine Melzner

nadine.melzner@tum.de

Extended author information available on the last page of the article 


\section{Problem background}

An enduring theme of CSCL research has been the question of how computer-supported collaborative learning can be structured so that learning outcomes at the individual level (such as knowledge acquisition; e.g., Haake and Pfister 2010) or at the group level (such as quality of a group product; e.g., Popov et al. 2017) can be improved when compared to unstructured CSCL. Much of this research has been centered on the concept of collaboration scripts (e.g., Fischer et al. 2013; Rummel et al. 2009). Collaboration scripts scaffold the collaboration process within groups by specifying, sequencing and distributing activities and roles among the learners of a group (Kollar et al. 2006). Even though such scripts generally have been shown to be effective (Vogel et al. 2017), their application "in the wild", i.e., in informal, selfguided learning contexts, is not unproblematic, as scholars have criticized collaboration scripts for possibly over-structuring the learning process so that collaboration might become a highly coercive experience ("over-scripting"; Dillenbourg 2002), though recent work challenges this concern (Radkowitsch et al. 2020). Especially self-organized groups, i.e., groups that students form completely voluntarily based on their own initiative outside regular classroom contexts (e.g., to jointly study for an upcoming exam), might find discomfort in following such finegrained externally imposed instructions. It is believed that this, in turn might even result in hampering effective learning (Raes et al. 2016; Vauras et al. 2003).

Although it is a very common form of collaborative learning, CSCL research has not extensively addressed self-organized collaborative learning thus far. Exceptions are studies by Hadwin et al. (2018) and Volet et al. (2009), who suggested that groups need help in joint planning (e.g., to help learners share their understanding of the given tasks) or in the selection of effective strategies (e.g., to help them ask effective questions). Nevertheless, collaboration in such studies was still structured at least in the sense that students were obliged to work at the university, to collaborate mainly using a computer, and to work uniformly on predetermined tasks for a predetermined number of study meetings. Thus, evidence on how completely selforganized groups regulate their learning in authentic contexts is still very scarce. This is regrettable, especially in the light of the current COVID-19 crisis, during which self-organized, technology-enhanced collaboration might have tremendous potential to enhance learning. Therefore, this study tries to uncover what differentiates successful from less successful selforganized collaborative learning, in an attempt to derive implications for further research on how to design instructional support for this kind of (computer-supported) collaborative learning.

In the present article, we conceptualize collaboration in self-organized study groups as an instance of (socially) self-regulated learning (Järvelä and Hadwin 2013) that requires groups to make decisions on their own learning process (e.g., concerning questions such as when and how long to meet, how to approach comprehension problems, or what technology to use during collaboration) (Zimmerman and Moylan 2009). Then, we describe typical problems during self-organized collaborative learning, thereby differentiating between coordinationrelated problems, motivational problems, and comprehension-related problems (Järvelä and Järvenoja 2011; Kirschner et al. 2008). Based on this, we develop a theoretical model that systematically embeds three precursors of students' satisfaction with their group learning experience into the regulatory process. We assume that groups should be more satisfied with their group learning experience the more they (a) have a homogeneous problem perception and (b) use strategies that are immediate with respect to resolving the given regulation problem, and the more intensively they (c) apply regulation strategies. We tested these assumptions in an 
empirical study involving $N=122$ students from $N=52$ completely self-organized groups studying for their upcoming exams from a broad range of disciplines at 10 German universities. The students were all asked to document their study meetings as well as their satisfaction with each study meeting via questionnaires.

\section{Conceptualizing self-organized collaborative learning}

In order to conceptualize self-organized collaborative learning, we refer to two prominent theoretical models from previous research. The first model is Zimmerman's cyclical phase model (Zimmerman and Moylan 2009), which provides a rationale to describe the process of self-regulated (i.e., individual) learning. This model differentiates between (1) a forethought phase, a (2) performance phase, and (3) a self-reflection phase, during which learners regulate their learning. Even though this model refers to individual self-regulated learning, it informs our theoretical understanding of self-organized collaborative learning for at least two reasons: First, as also in self-organized collaborative learning, problems are not already known to learners before the start of the learning process. Zimmerman's model takes this into account through the cyclical phase structure of regulation. Secondly, the cyclical phase structure is reflected in the nature of repeated study meetings across the exam phase (Järvelä et al. 2019; Zimmerman 2000).

To illustrate this line of argument, Zimmerman's model will be applied to the selforganized collaborative learning in preparation for an upcoming exam in the following scenario: During the (1) forethought phase, the group is confronted with the task to prepare for the exam. As part of the task analysis, the group members set the goal to study the learning material necessary for the exam. Strategic planning is represented by the decision to form a study group for the purpose of collaborative exam preparation as well as by the organization of a study meeting to learn together. During the (2) performance phase, group members meet and engage in collaborative learning. They do so by executing learning strategies (= self-control) and continuously monitoring the learning process (= self-observation). In the (3) self-reflection phase, the learners assess whether the learning process was successful, which in turn influences follow-up reactions, such as satisfaction with the learning experience. Based on their appraisal of the processes and results of their meeting, they decide upon the organization of the remaining time for the current meeting or the organization of future meetings. At this point, the next forethought phase begins. Based on the assumption that most regulatory problems arise in the performance phase, this study focuses on processes in this phase. We conceptualize the regulation process during the performance phase as follows (see Fig. 1): Through metacognitive monitoring, the individual members of a group (1) perceive and classify an obstacle to successful learning. To restore effective learning conditions (2) effective strategies must be selected and (3) executed with a certain intensity. These three processes (problem perception, selection of regulation strategies, execution intensity) should then affect the successfulness of the groups' regulation efforts.

As a second theoretical basis for the present study, we use the conceptualization for coregulated learning proposed by Järvelä and Hadwin (2013) that has recently gained considerable attention in CSCL research (Järvelä et al. 2018). Their model differentiates three modes of regulation during collaborative learning: self-regulation, i.e., where learners regulate their own learning processes (self-level), co-regulation, i.e., where learners support one another (colevel), and socially shared regulation, i.e., where the collective regulation effort is applied by 


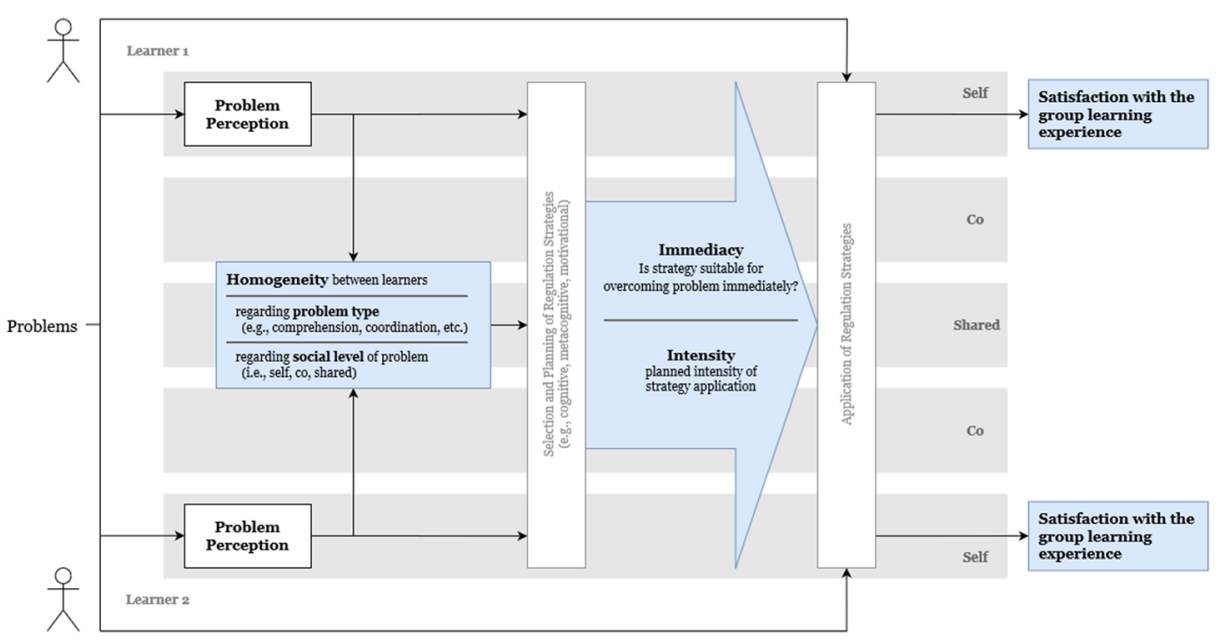

Fig. 1 Theoretical model of the regulation of problems during collaborative learning in self-organized study groups (visualization inspired by Wecker and Fischer 2014). Concepts in bold face are measured in the present study

the group (shared level). Self-, co-, and shared regulation as three modes of social regulation add a "vertical" dimension to our previously defined "horizontal" conceptualization of collaborative problem regulation. Figure 1 illustrates this for an example involving two learners.

While the initial problem perception is an individual process, the subsequent reactions (i.e., both strategy planning and strategy application) can be executed at each social level. Accordingly, the perception of a problem can remain hidden at the self-level, but it can also be communicated to other group members, or other group members can infer it from another group member's behavour. In the same way, regulation strategies might be chosen by each of the learners, and carried out with varying intensity towards the learner herself (self), chosen by and carried out towards single other group members (co), or chosen by and carried out as a group (shared). For the purpose of the present study, this vertical dimension is necessary from a theoretical perspective to conceptualize similarities and differences in problem perceptions between groups. Therefore, in the empirical study reported later, we also differentiate regulation strategies that can be observed in groups at the three social levels suggested by this model.

\section{Typical problems during self-organized collaborative learning}

Learning in groups is challenging when there is no external structure, i.e., when groups are completely free to decide when, where, what, and for how long to study (Volet et al. 2009). Based on prior research on collaborative learning and problem regulation (Järvelä et al. 2016; Järvenoja et al. 2019; Malmberg et al. 2015), we differentiate between three kinds of problems that may occur during self-organized collaborative learning: namely, (a) coordination-related, (b) motivational, and (c) comprehension-related problems.

Coordination-related problems may arise when group members set different priorities for studying exam content, or when they set different learning goals (Järvelä and Järvenoja 2011; Järvelä et al. 2008). For example, Järvenoja and Järvelä (2009) provide an in-depth analysis of two groups in which two out of four members differed from the rest of the group regarding their goals ("goals to maintain and increase one's own well-being, such as avoiding stress" 
versus "social goals" such as "having a good time and enjoying the experience"). Their analyses showed that this incongruence of goals caused serious problems for a purposeful collaboration within the group.

Motivational problems may emerge when group members struggle to see relevance in the exam topics or when they consider them boring, although it seems that motivational problems are often not determinable in detail (Järvelä et al. 2015). Näykki et al. (2014) provide examples for these kinds of problems. They had 22 education students work together in groups of four to five over a twelve-week course. They found that groups frequently experienced motivation problems, such as low interest in the learning task and low participation. According to Järvelä et al. (2010), problems of this type often result in declining effort, engagement and participation, and have been identified as causal for the development of socio-emotional problems in groups (Järvenoja and Järvelä 2005).

Finally, comprehension-related problems may arise when learning tasks are difficult for learners (Koivuniemi et al. 2017), when learners have problems understanding each other's thinking (Kirschner et al. 2008), or when the learning material is ill-structured (Näykki et al. 2017). For instance, in a study by Malmberg et al. (2015), 103 students worked on collaborative tasks in groups of three to four during a two-month multimedia course. To facilitate collaboration, groups used an online learning environment that prompted them to report problems they experienced during collaboration. Comprehension-related problems (e.g., "The concept of treatment is not clear for us", p. 15) were by far the most frequent problems.

\section{Homogeneity of problem perception}

Before being able to use regulation to address a problem, learners need to recognize the presence and nature of their problem (Järvelä et al. 2019). While this is already difficult in individual learning settings (e.g., Winne and Hadwin 1998), it becomes even more difficult in groups, as the single group members may have divergent views on the problems their group is facing in a given situation (Splichal et al. 2018). According to Järvelä and Hadwin (2013), the perception must be shared or co-constructed between learners and their learning partner(s) in order to validate, correct, or complete individual perceptions of the problem. This can be seen as fostering intersubjectivity, specifically intersubjectivity regarding problem perception, which is conceptualized as a distinctive characteristic of functional groups (Stahl 2015). Thus, we assume that successful groups should be more able to develop a homogeneous joint problem perception with their members, in comparison to less successful groups (Bodemer and Dehler 2011). This process does not necessarily have to take the form of a discussion about the perceived problems. It may also take place when learners infer their partners' problem perceptions from an observation of their behavior and then adapt their own perception individually (Volet et al. 2009). Holding homogeneous problem perceptions should enable group members to take actions that are promising for solving the current problem (Hadwin et al. 2018; Miller and Hadwin 2015) and to collectively monitor and evaluate joint regulation and regulate success more easily than when problem perceptions are heterogeneous within a group (Hurme and Järvelä 2005; Hurme et al. 2006).

As can be seen in Fig. 1, we distinguish between two types of homogeneity regarding the problem perception: (a) homogeneity regarding the perception of the types of regulation problems, and (b) homogeneity regarding the social level at which these problems materialize within the group.

Homogeneity regarding the perception of types of problems This kind of homogeneity is present when all members of a group hold a shared view regarding the type of problem the 
group is currently facing (see Splichal et al. 2018). For example, two students of a dyadic study group might both perceive a motivational problem in their group situation. This would be a shared representation of the problem, and should in turn facilitate the decision for an appropriate strategy to remedy this problem (Barron 2003; Bodemer and Dehler 2011). In contrast, if one of the students currently perceives the "lack of comprehension of the subject matter" as a salient problem, while her learning partner instead perceives a coordinationrelated problem as being prominent, the result would be a heterogeneous problem perception. This heterogeneous view might interfere with making decisions regarding how to proceed (Aggarwal and O’Brien 2008).

Homogeneity regarding the social level at which a problem is located Homogeneity can also be considered in terms of the social level of regulation at which group members perceive problems. Here, Järvelä and Hadwin's (2013) differentiation of the self-, co- and shared-level proves helpful: Based on this differentiation, a homogeneous problem perception would be present, for example, when all members of a group perceive a comprehension problem on the side of another group member, and when that person also recognizes having this problem. The problem perception would instead be heterogeneous when some group members locate the problem at the shared-level, while others attribute it to just one member of the group. Again, such heterogeneity might make the selection of appropriate regulation strategies more difficult compared to cases in which groups have homogeneous perceptions.

So far, only a few studies have investigated questions related to the homogeneity or heterogeneity of problem perception in collaborative learning. The few studies that exist have instead focused on homogeneity regarding the type of problem being present, but have largely seemed to ignore homogeneity regarding the social level at which these problems occur. For example, Järvelä et al. (2013) asked group learners to report their most salient problem at the shared-level as a group. Even though the authors observed that a group with homogeneous problem perceptions not only showed high levels of shared regulation but also high-quality group outcomes, this study did not look into the possible effects of heterogeneity of problem perceptions across group members. Further, as students were prompted to negotiate their most salient problem, it remains unclear whether students would negotiate their problem perceptions also without being prompted externally.

\section{Immediacy and intensity of strategy use}

Once learners have built a perception of a particular problem (whether this perception is shared among the group members or not), the next step is the selection of strategies that seem appropriate to remedy this problem. To classify learning strategies, several suggestions exist in the literature that differ in nuances (e.g., Engelschalk et al. 2015; Friedrich and Mandl 2006; Zimmerman and Moylan 2009). For the purpose of this article, we integrated these classifications into a comprehensive and multi-dimensional scheme (see Table 1). This was necessary to be able to precisely map these strategies to the aforementioned problems. We propose a classification that differentiates four main categories of strategies: (a) cognitive, (b) metacognitive, (c) resource-oriented motivational, and (d) resource-oriented non-motivational strategies. Cognitive strategies are defined as strategies for creating or improving understanding (e.g., explaining central concepts to be learnt), retrieving information (e.g., rote learning), or cognitive organization of knowledge structures (e.g., by creating a mind-map). Metacognitive strategies are strategies for planning and regulation, or for reflection and 
evaluation of the learning process in order to select, evaluate, and fine-tune activities of successful learning. Examples include planning strategies (e.g., developing a study plan), and evaluation strategies (e.g., assessing whether the pace of learning is appropriate). Resource-oriented motivational regulation strategies are strategies that serve to establish and/or maintain learning motivation in order to support a continuous interaction with the learning material and with the learning partners. Examples are reward strategies (e.g., eating candy after having finished another hour of studying) or the enhancement of situational interest (e.g., starting the learning process with subjectively interesting topics). Finally, resource-oriented, non-motivational strategies are strategies that improve the general conditions of the learning process, such as providing enough time to study, ensuring attention, or gathering necessary learning materials. They include, for example, time management and environmental control strategies (e.g., choosing a quieter place for studying).

Immediacy of strategy use In the present article, we assume that the effectiveness of a chosen strategy for regulating a given problem depends on how immediately it is applied with respect to the onset of the associated problem (see also Eckerlein et al. 2019; Engelschalk et al. 2015). Immediacy is thus defined as a measure of the fit of the selected strategies to the aim of successful regulation of a given problem. We argue that using an immediate strategy makes it more likely for learners to successfully solve a regulation problem, compared to using a non-immediate strategy. For example, if a learner does not understand a difficult concept, she might ask a fellow student for an explanation. If her partner's explanation is correct, this would be a strategy that would immediately solve the problem at hand. However, she might also try to motivate herself through setting a reward for successful problem solving in order to stay engaged in the learning process. This might be a strategy to solve a different problem (i.e., the tendency to avoid the task), but the problem of not understanding the subject matter would still be present after she has used this strategy. Therefore, the latter strategy would not be considered immediate for that specific problem.

The idea that strategies differ in their immediacy for regulating different problems is not new. With respect to comprehension problems, Leutner et al. (2007), for example, suggested that problems that arise from being confronted with confusing learning material could be controlled immediately with organizational strategies (e.g., summarize learning content; Zheng et al. 2017). Similarly, Neber (2006) proposed that asking topic-related questions might be a strategy specifically for the purpose of overcoming problems that result from a lack of prior knowledge, whereas metacognitive strategies would address such problems only indirectly.

For motivational problems, Schwinger and Otterpohl (2017) assume that any motivational regulation strategy may theoretically be applied for immediate remediation of any type of motivational problem. Thus, from their perspective, differentiating between motivational regulation strategies that are immediate versus strategies that are not does not seem promising. However, Vollmeyer (2006) argues that motivational problems that arise from being confronted with boring learning material may be overcome with strategies for increasing situational interest, while Sansone and Thoman (2005) suggest using reward strategies in this situation instead. Furthermore, Vollmeyer (2006) suggests that general motivational problems (e.g., low motivation to engage with learning material) can be overcome with strategies that serve to increase personal significance, highlight conditions or constraints of the current learning situation, or offer rewards. It thus seems that motivational regulation strategies might be regarded as having a somewhat larger bandwidth than, for example, cognitive strategies (i.e., in many cases, the same strategy might be immediate for the regulation of more than one problem). Yet, building on Sansone and Thoman (2005) and Vollmeyer (2006), we regard it 
Table 1 The different strategy types along with examples from the data

Strategy
Cognitive
Organizational Strategies
(OS)
Strategies for Improving
Comprehension (SIC)
Strategies for Closing
Gaps in Prior
Knowledge (CGP)
Strategies to Resolve
Differences in
Understanding (RDU)

Surface-Oriented and Retention Strategies (SRS)

Metacognitive

Planning and Regulation of the Learning Process (PRL)

Reflection and Evaluation of the Learning outcomes (REL)

Motivational

Reward Strategies (RS)

Increasing Situational Interest (ISI)

Increasing Personal Significance (IPS)

Mastery and Performance-Related Self-Talk (approach and avoidance) (MPS)

Ability-Related Self-Talk (AST)

Declaring Successful Self Control as a Goal (DSG)

Highlighting Frame Conditions or Constraints (HFC)
Description

Strategies to get an overview over, to structure, or to reduce learning content

Deep learning strategies building on prior understanding of the subject matter like elaboration, questioning, explication, reflection, application

Strategies with a relatively high degree of elaboration that serve to close gaps in prior knowledge in generating a further differentiable knowledge base

Strategies for presenting and justifying own understanding of the learning content and adopting the perspective of others to align, adopt, or differentiate cognitive structures between learners

Strategies to consolidate knowledge by memorizing or repeating learning content

Strategies aiming at managing the process of learning itself instead of the subject matter.

Strategies to measure progress, testing abilities, assessing and judging learning outcomes, or checking for correct responses

Setting up or reminding of a positive consequence following the learning activity

Strategies to make the process of learning or the subject matter more fun, exciting, or interesting

Strategies relating the subject matter or learning activity to own personal life, interests, or goals, or looking for relevance in other ways

Reminding of increasing competence (= mastery goal), demonstrating competence (= performance goal), or avoiding development or demonstration of incompetence as goals in themselves

Strategies to assure oneself/other group members/the group that one's ability is sufficient to cope with the subject matter or the exam

Convincing oneself/other group members/the group that being able to hold on/being disciplined is a valuable goal in itself

Pointing to basic conditions that make exploiting the current learning opportunity necessary, urgent, or beneficial
Example from data

"We created a mind map to structure the topic."

"The mutual explanations were helpful for the whole group".

"I first clarified the theory on the topic."

"I have justified my conception of the task."

"We repeated the subject matter together."

"I advised her to take a closer look at it at home, as I do not want it that much in detail."

"I specifically ask myself if I have understood everything."

"I told her that there is only little content left and that we have already done most of the work."

"We tried to make learning less boring by using humor."

"I reminded us of the relevance for the job."

"I pointed out to my partners that he was better at the last exam than me, and that I would like to turn this around the next time."

"I reaffirmed their understanding of the subject matter."

"Gritted my teeth until I understood it."

"Made others be more aware of how much more material there is to learn and how close the exam is." 
Table 1 (continued)

\begin{tabular}{|c|c|c|}
\hline $\begin{array}{l}\text { Highlighting Group } \\
\text { Utility as a Goal (HGU) }\end{array}$ & $\begin{array}{l}\text { Reminding of the benefits of being in a } \\
\text { group or the role one has to play to } \\
\text { make the group experience successful }\end{array}$ & $\begin{array}{l}\text { "Being a group makes it much easier to } \\
\text { actually be productive. You do not want } \\
\text { to be the one who thwarts progress, just } \\
\text { because you do not feel like it." }\end{array}$ \\
\hline $\begin{array}{l}\text { Emotional Contagion } \\
\text { (ECG) }\end{array}$ & $\begin{array}{l}\text { Trying to catch up with the positive } \\
\text { spirit of other group members, to inspire } \\
\text { others, or to avoid dragging others } \\
\text { down }\end{array}$ & "I let myself carry away by the others." \\
\hline $\begin{array}{l}\text { Unspecific Motivational } \\
\text { Regulation Strategies } \\
\text { (UMS) }\end{array}$ & $\begin{array}{l}\text { Strategies aiming at increasing } \\
\text { motivation to study, though described } \\
\text { so generally that they cannot be } \\
\text { categorized more specifically }\end{array}$ & "I motivated others." \\
\hline \multicolumn{3}{|c|}{ Resource-Oriented (Non-Motivational) } \\
\hline $\begin{array}{l}\text { Time Management and } \\
\text { Coordination (TMC) }\end{array}$ & $\begin{array}{l}\text { Strategies that address the use of time } \\
\text { like planning pauses, avoiding private } \\
\text { chats, preparing in advance to save time } \\
\text { while meeting, or setting the time frame } \\
\text { for the meeting. }\end{array}$ & $\begin{array}{l}\text { "I suggested to effectively use the } \\
\text { time." }\end{array}$ \\
\hline $\begin{array}{l}\text { Environmental Control } \\
\text { (EC) }\end{array}$ & $\begin{array}{l}\text { Strategies aiming at managing } \\
\text { surrounding conditions in a way to } \\
\text { foster learning }\end{array}$ & $\begin{array}{l}\text { "I have asked my classmates to turn off } \\
\text { all the phones." }\end{array}$ \\
\hline $\begin{array}{l}\text { Knowledge and } \\
\text { Information Management } \\
\text { (KIM) }\end{array}$ & $\begin{array}{l}\text { Strategies to organize or share resources } \\
\text { containing learning material (in contrast } \\
\text { to organizing the learning content itself } \\
\rightarrow \text { OS) }\end{array}$ & $\begin{array}{l}\text { "We did provide our individual } \\
\text { documents." }\end{array}$ \\
\hline $\begin{array}{l}\text { Attention Management } \\
\text { (AM) }\end{array}$ & $\begin{array}{l}\text { Strategies that serve to direct the focus } \\
\text { of attention at the subject matter or } \\
\text { learning process }\end{array}$ & $\begin{array}{l}\text { "Redirected further discussions back to } \\
\text { the topic" }\end{array}$ \\
\hline $\begin{array}{l}\text { Effort Management } \\
\text { (EM) }\end{array}$ & $\begin{array}{l}\text { Strategies to manage workload and } \\
\text { engagement, often by splitting a task } \\
\text { into subtasks and assigning them to } \\
\text { different group members }\end{array}$ & "I engaged in the study group." \\
\hline $\begin{array}{l}\text { External Resource } \\
\text { Management (ERM) }\end{array}$ & $\begin{array}{l}\text { Reaching out to external resources } \\
\text { outside the study group for support, or } \\
\text { looking something up }\end{array}$ & $\begin{array}{l}\text { "We searched the internet for } \\
\text { explanations." }\end{array}$ \\
\hline $\begin{array}{c}\text { Care of Social } \\
\text { Atmosphere (CSA) }\end{array}$ & $\begin{array}{l}\text { Strategies to establish or to maintain a } \\
\text { positive, learning-friendly atmosphere } \\
\text { between group members }\end{array}$ & $\begin{array}{l}\text { "I tried to be objective and to ignore the } \\
\text { discrepancies between the two } \\
\text { learners." }\end{array}$ \\
\hline
\end{tabular}

promising to analyze in more detail what motivational strategies are immediate for the regulation of which types of motivational problems.

For coordination-related problems, research on which strategies would be immediate and which ones would not largely appears to be missing. A typical coordination-related problem might be that the members of a group differ in their ideas for how to proceed with the task: One group member might want to revisit an earlier topic, while other group members might prefer improving their understanding of a new topic. To regulate this problem, the group might decide to apply a motivation regulation strategy like planning to reward itself after the study meeting. Alternatively, the group might decide to discuss and negotiate their divergent plans and find an agreement on how to proceed. For the given situation, we consider the latter strategy to be more immediate than the former strategy because communicating one's own plans and intentions is necessary prior to negotiating the further joint learning process. Applying a reward strategy, in contrast, would not solve that problem and therefore would not be immediate.

Empirical studies that look at the effects of the use of immediate versus non-immediate strategies on learning outcomes in collaborative learning are rare. A study by Hadwin et al. 
(2018) showed that from the perspective of collaborating learners, certain strategies (e.g., process control strategies) were subjectively more effective than others, but only when particular scaffolds were present (in this case: a nominal visualization that provided information about the range, but not the frequency, of task perceptions and goals or standards identified by other members of a group). When other or no scaffolds were used, this observation could not be made. Nevertheless, these findings can be regarded as evidence that at least from learners' subjective perspectives, certain strategies seem to be more immediate than others (at least in certain situations). In addition, and as shown, there are good theoretical reasons why applying immediate strategies should have a more positive effect on learning outcomes than the application of non-immediate strategies.

Intensity of strategy use In addition to the potentially positive influence of immediacy of strategy use on the learning outcomes of self-organized group learning, our theoretical model in Fig. 1 assumes also that the intensity by which (learners in) groups apply strategies might have positive effects on learning outcomes. We define intensity of strategy use as the quantitative frequency by which learners apply different strategies. Our hypothesis is that the more intensively students use regulation strategies, the better their learning outcomes would be. The reason is that at least in difficult situations, applying a certain strategy only once (even an immediate one) or applying just one strategy repeatedly may not be enough to solve the current problem. Instead, positive effects on learning outcomes should become more likely the more students apply the same strategy or the strategy along with other strategies. In individual learning settings, evidence for this hypothesis comes from a study by Eckerlein et al. (2019). They found that the quantity by which students reported using motivational regulation strategies during exam preparation had a significant impact on invested effort and exam grade. Schwinger et al. (2009), though, failed to observe a direct effect of intensity of strategy use on exam grade, but found an indirect effect mediated by effort.

In collaborative learning contexts, evidence regarding the effects of intensity of strategy use on learning outcomes is mixed as well. On the one hand, Schoor and Bannert (2012) tested the intensity of strategy use at the self- versus social level (to be understood as including both coand shared regulation) of 42 students during a computer-supported collaborative learning task and found no relation between the intensity of strategy use and performance. On the other hand, using qualitative analyses, Järvelä et al. (2013) report evidence that a more intense use of strategies ("We tried and tried.") was related to a higher quality of group product.

In sum, there is at least some empirical evidence suggesting that the intensity by which learners and groups use regulation strategies as they study might be positively related to important learning outcomes. While previous studies have mostly looked at the effects on outcomes such as effort and exam scores, the current study investigates the effects of intensity and immediacy of strategy use on students' satisfaction with the group learning experience.

Satisfaction with the group learning experience as an effect of successful regulation.

According to our theoretical model (Fig. 1), we assume that a homogeneous problem perception (both with respect to the type of the problem and the social level at which the problem occurs) and both the immediacy and intensity of strategy use should have positive effects on learning outcomes. According to Winne and Hadwin (1998), such outcomes can be very diverse and include aspects such as academic performance, conceptual understanding, attitudes towards the learning topic, or students' self-efficacy. As mentioned, and in line with Zimmerman and Moylan (2009), we focus on satisfaction with the group learning experience as an outcome variable. The degree of satisfaction can be regarded as a product of the self- 
reflection phase (Zimmerman and Moylan 2009) and depends on students' evaluations of how well their strategies worked out and of the degree to which they reached their learning goals. Concerning self-organized study groups in the exam phase, it can be assumed that the main goal these students set for their meetings is to better understand or to remember the required concepts in order to perform well on their exams (Volet et al. 2009). If these appraisals are positive, learners should be satisfied with their group learning experience (Hadwin et al. 2018).

Empirical findings support this kind of reasoning: Järvelä et al. (2010) found a qualitative association between effective (social) regulation and satisfaction, at least for a single case. Using quantitative methods with the data of $N=203$ students, Noroozi et al. (2019) found knowledge gain to be positively associated with high satisfaction ratings. Thus, taking into account that Zimmerman and Moylan (2009) also argue that effective regulation leads to higher satisfaction ratings, we treat satisfaction with the group learning experience as an important outcome of collaborative learning and will therefore use it as an outcome measure in the empirical study reported in this article.

\section{Research questions and hypotheses}

We empirically tested the hypotheses represented in the theoretical model in Fig. 1 with a sample of university students who had voluntarily formed self-organized groups to study for their upcoming exams. Since regulation efficacy depends on context (Splichal et al. 2018), we considered it necessary to reach a high level of external validity in our study. Therefore, we recruited real study groups from a broad range of disciplines to participate in our study. We formulated three research questions: First, we asked whether learners with homogeneous problem perceptions within their groups would be more satisfied with their group learning experience than learners with heterogeneous problem perceptions $\left(\mathrm{RQ}_{1}\right)$. We expected that the more homogeneously groups perceived their problem, both with respect to the type of the perceived problem and to the social level at which the problem is located, the more satisfied with the group learning experience they would be $\left(\mathrm{H}_{1}\right)$. Second, we asked whether learners' satisfaction with the group learning experience would increase with an increased use of immediate strategies. $\left(\mathrm{RQ}_{2}\right)$. We assumed that satisfaction with their group learning experience would be higher, the more immediate strategies learners applied to solve their most salient problem $\left(\mathrm{H}_{2}\right)$. Third, we asked whether learners' satisfaction with the group learning experience is associated with the intensity of strategy use within the group. $\left(\mathrm{RQ}_{3}\right)$. Here, we expected satisfaction with the group learning experience to increase with higher and to decrease with lower intensity of strategy use $\left(\mathrm{H}_{3}\right)$.

\section{Method}

\section{Sample}

Participants were $N=175$ university students from 90 different self-organized study groups ( $74.29 \%$ female, $25.14 \%$ male, $0.57 \%$ other). They had an average age of 22 years $(M=22.26$, $S D=2.68)$ and were on average in the fifth semester $(M=4.64, S D=3.03)$ of their current study subject and in the sixth university semester overall $(M=6.21, S D=3.85)$. Participants came from various study programs (e.g., education, teacher education, law, computer science, 
mathematics, biology, psychology, theology). Subjects were recruited online through social media at ten German universities, as well as through direct interpersonal communications on campus and in class. The number of learners from each study group who agreed to participate in the study and documented their study meeting varied between 1 and 5 learners, with two members being the most frequent number of participating group members $(23.27 \%)$. This means that the groups were free to choose how many learners from their group participated in the study. For example in a group of three learners, only one person might have been willing to participate in the study, resulting in only one person documenting the study meetings of three people.

Groups studied in a completely self-organized way, i.e., they were not provided with any structuring aids such as scaffolds by the experimenters. Thus, the learners had to decide for themselves which tasks or activities they would work on with the goal of preparing for their exams without having been given tasks "from outside". The self-organized study groups were also free to hold meetings face-to-face or via digital technology.

After each study meeting, participants were asked to individually answer an online questionnaire. They were rewarded with EUR 14 if they completed the questionnaire three times. For each additional questionnaire, they were reimbursed with an additional EUR 3. The maximum number of questionnaires we asked students to complete was ten (EUR 35). Questionnaires on further meetings could be answered on a voluntary basis, but without further compensation. Because homogeneity could only be determined when there was data from at least two persons of the same group at a single measurement point available, only data of $N=122$ students from 52 study groups was included in the analyses. Most groups documented three study meetings, and ended participation in the study somewhere between the third and the tenth meeting.

\section{Instrumentation}

For data collection, we used a self-report questionnaire, which represented a modified version of the Adaptive Instrument for Regulation of Emotions (AIRE; Järvenoja et al. 2013). In its original version, this instrument presents 12 coordination-related problems and asks learners to indicate the extent to which they experienced each of these problems during collaboration, using a five-point Likert scale (from $0=$ Did not happen to $4=I t$ was a big challenge). An exemplary item is: We seemed to have incompatible styles of working. To measure students' problem perception, they are subsequently asked to mark their most salient regulation problem. Next, the AIRE questionnaire presents a list of strategies and asks students to indicate to what extent they applied each of these strategies to regulate their emotions that were evoked by the most salient problem. Finally, students are asked to indicate how satisfied they were with the group work on a four-point Likert scale (from $1=$ not satisfied at all to $4=$ fully satisfied).

We expanded this questionnaire by adding two motivational and three comprehensionrelated problems for a more complete coverage of the areas in which study groups might encounter problems. The formulation of these problems was oriented towards the problems mentioned in related research such as Malmberg et al. (2015) and Näykki et al. (2014). Further, we used the category distraction problems from the AIRE, but categorized it as a motivational problem. We further removed the three problem types of different priorities, personal living conditions and problems to connect very well with one other, to make the instrument more concise, as these problems were the most unlikely to occur in the context of self-organized groups where group formation is typically based on factors such as joint exams and 
interpersonal affinity. Also, we included a text box where students were asked to describe their most salient problem in their own words so we were able to check if groups actually described the same problem when they indicated the same problem type as their most salient problem. Further, we dropped the quantitative rating of employed regulation strategies. Instead, we asked participants to name the strategies they used to regulate their most salient problem at the self-, co- and shared level in an open answer format. In particular, at the self-level: "What did you personally think, do or say to ensure high quality of your own learning in this situation?"; at the co-level: "What did you personally think, do, or say to ensure high quality of the learning of individual others in this situation" and for the other possible direction of coregulation: "What did you personally think, do or say to persuade other group members in this situation to ensure a high quality of your own learning?"; finally, at the shared level: "What did you as a group think, do or say to ensure high quality of the learning of the whole group in this situation"; Järvelä and Hadwin 2013). Using an open answer format, we tried to reduce response bias related to social desirability. Finally, we expanded the four-point Likert scale for the satisfaction rating by three additional scale points in order to obtain a better differentiation of regulation efficacy. Subjects were asked to answer the questionnaire directly after each study meeting, but independently from each other. They received a reminder e-mail every evening at the same time in case they forgot to answer the questionnaire. The questionnaire that learners had to fill out was the same for each group member and study meeting.

\section{Variables}

Homogeneity regarding the perception of types of problems To capture the group's homogeneity regarding the perception of the type of problem, participants were first asked to rate on a five-point scale ( $1=$ Is not true at all, $5=$ Is absolutely true) how intensively the group learners experienced each of the 14 listed problems during their study meeting. The variable was then operationalized as the variance within each group for each of the 14 problems. The variances for each problem type were then averaged across all problem types for each group. The mean variance then was z-standardized before the sign of this variable was flipped so that higher values would represent higher levels of homogeneity rather than heterogeneity.

Homogeneity regarding the social level at which a problems is located Homogeneity of problem perception with respect to the social level was operationalized via the agreement in the perceptions of the location of the most salient problem between all members of a group. To measure this variable, participants rated on a five-point rating scale how strongly they experienced the problem they marked before as the most salient one (see section above) at the self-, co- and shared level (one item per level; 1 = Is not true at all, $5=$ Is absolutely true). To determine homogeneity at the social level, we assigned the value ' 1 ' when perceptions of all group members matched, and the value ' 0 ' when one or more group member's perception(s) of the social level at which the most salient problem was located did not match with the perceptions of the rest of the group within a specific meeting. For example, when one learner in a dyad located the problem at the co-level, then the group was coded as homogeneous only when the other learner in that dyad did the same.

Immediacy of strategy use To measure immediacy of strategy use, we developed a coding scheme to classify the learning strategies participants reported within one of four categories: (a) cognitive strategies (e.g., organizational strategy), (b) metacognitive strategies (e.g., planning 
and regulation of the learning process), (c) resource-oriented, motivational strategies (e.g., reward strategies) and (d) resource-oriented, non-motivational strategies (e.g., time management and coordination strategies). Based on established strategy typologies (Engelschalk et al. 2015; Friedrich and Mandl 1992), we differentiated between 26 categories: Twenty-four specific strategy types (see Table 1), one Other category for nonspecific strategies, and one None category for answers that did not describe any strategy. Two independent and trained coders rated all answers and reached sufficient interrater agreement (Cohen's $\kappa=.85$ ).

In a second step, the first and second author of this article discussed which of the 24 strategies would be immediate for each of the 14 regulation problems. In line with our theoretical assumptions, a strategy was considered immediate when, in principle, it would help to solve the current problem. It was regarded as non-immediate when an application of the strategy would not solve the specific problem. This resulted in the classification in Table 2.

In a third step, each questionnaire was coded for whether the participant named at least one strategy that would be classified as immediate (in this case, the value ' 1 ' would be given) or not (in this case, the value ' 0 ' would be given) regarding the most salient problem that the participant noted perceiving. Subsequently, this binary variable was z-standardized.

Intensity of strategy use To operationalize intensity of strategy use, we summed up the frequencies of all strategies a person reported for each meeting. For the subsequent analyses, this variable was z-standardized.

Satisfaction with the group learning experience Satisfaction with the group learning experience was measured using one item that asked students to rate their satisfaction with the respective meeting on a seven-point rating scale $(1=$ Totally unsatisfied, $7=$ Totally satisfied $)$. The resulting variable was also z-standardized. Though the reliability of this one item measure cannot be determined directly, the multiple measurements collected for each participant within the longitudinal design might be considered to lend sufficient reliability for this outcome measure.

\section{Statistical analysis}

As preliminary analyses, we first calculated CFAs in order to examine if the initially formulated three-problem structure would be supported by the data. We further assessed the validity of our classification of immediate and non-immediate strategies for each problem by calculating absolute and relative frequencies by which each problem was regulated with an immediate versus a non-immediate strategy. In addition, we calculated for each problem whether immediate strategies were chosen more frequently than expected by chance.

To test whether homogeneity of problem perceptions, immediacy of strategy use and intensity of strategy use are associated with satisfaction with the group learning experience, we conducted hierarchical linear modelling using $R$ 3.5.2 (R Development Core Team 2018) and the packages lmerTest 3.1-0 (Kuznetsova et al. 2017) with lme4 1.1-21 (Bates et al. 2015). Using HLM allowed for the analysis of the effects of each of the three predictor variables on satisfaction with the group learning experience as well as of the temporal variability of satisfaction with the group learning experience. This also allowed for an analysis of the variability of inter-individual and inter-group differences regarding satisfaction with the group learning experience. To account for the three-level data structure (observations in persons in groups; Singer and Willett 2003), random intercepts were included (REML estimation). 
Table 2 Overview over the strategy types that can be considered as strategies for an immediate regulation of the listed problems

\begin{tabular}{|c|c|c|c|c|}
\hline \multirow[t]{2}{*}{ Specific Problem } & \multicolumn{4}{|c|}{ Strategies Immediately Addressing the Problem } \\
\hline & Cognitive & Metacognitive & Motivational & $\begin{array}{l}\text { Non- } \\
\text { Motivational }\end{array}$ \\
\hline \multicolumn{5}{|l|}{ Comprehension-Related Problems } \\
\hline $\begin{array}{l}\text { J. The group members have only } \\
\text { low prior knowledge of the } \\
\text { learning contents. }\end{array}$ & $\begin{array}{l}\text { SIC, } \\
\text { CGP, }\end{array}$ & & & ERM \\
\hline $\begin{array}{l}\text { L. The group perceives the learning } \\
\text { material as difficult. }\end{array}$ & OS, SIC & & & TMC \\
\hline $\begin{array}{l}\text { N. The group members perceive the } \\
\text { study material as confusing. }\end{array}$ & OS, SIC & & & \\
\hline \multicolumn{5}{|l|}{ Motivational Problems } \\
\hline $\begin{array}{l}\text { H. The group has distraction } \\
\text { problems. }\end{array}$ & & PRL & ISI, DSG, HFC, ECG & $\mathrm{EC}, \mathrm{AM}$ \\
\hline $\begin{array}{l}\mathrm{K} \text {. The group members have } \\
\text { motivational problems. }\end{array}$ & & & $\begin{array}{l}\text { RS, ISI, IPS, MPS, AST, } \\
\text { DSG, HFC, HGU, } \\
\text { ECG, UMS }\end{array}$ & \\
\hline $\begin{array}{l}\text { M. The group members consider the } \\
\text { study material to be boring. }\end{array}$ & & $\begin{array}{l}\text { RS, ISI, IPS, MPS, } \\
\text { DSG, HFC, } \\
\text { HGU, ECG }\end{array}$ & & \\
\hline \multicolumn{5}{|l|}{ Coordination-Related Problems } \\
\hline $\begin{array}{l}\text { A. The group members have } \\
\text { different goals for the meeting. }\end{array}$ & & PRL & & EM \\
\hline $\begin{array}{l}\text { B. The group members seem to } \\
\text { have incompatible working styles. }\end{array}$ & & PRL & & \\
\hline $\begin{array}{l}\text { C. The group members seem to } \\
\text { have different communication } \\
\text { styles. }\end{array}$ & & PRL & & \\
\hline $\begin{array}{l}\text { D. The group members understand } \\
\text { concepts / tasks differently. }\end{array}$ & $\mathrm{RDU}$ & PRL & & \\
\hline $\begin{array}{l}\text { E. The group members have } \\
\text { different ideas on how to proceed } \\
\text { with the task. }\end{array}$ & & PRL & & \\
\hline $\begin{array}{l}\text { F. The contributions of individual } \\
\text { group members are differently } \\
\text { strongly considered. }\end{array}$ & & & & EM \\
\hline $\begin{array}{l}\text { G. Not every group member always } \\
\text { dares to participate. }\end{array}$ & & & AST & EM \\
\hline $\begin{array}{l}\text { I. Not all group members have } \\
\text { enough time for the meeting. }\end{array}$ & & & & $\begin{array}{l}\text { TMC, KIM, } \\
\text { AM }\end{array}$ \\
\hline
\end{tabular}

Below are the full labels of each strategy (abbreviations in parentheses)

Cognitive: Organizational Strategies (OS), Strategies for Improving Comprehension (SIC), Strategies for Closing Gaps in Prior Knowledge (CGP), Strategies to Resolve Differences in Understanding (RDU), Surface-Oriented and Retention Strategies (SRS)

Metacognitive: Planning and Regulation of the Learning Process (PRL), Reflection and Evaluation of the Learning Outcomes (REL)

Resource-oriented, motivational: Reward Strategies (RS), Increasing Situational Interest (ISI), Increasing Personal Significance (IPS), Mastery and Performance-Related Self-Talk (approach and avoidance) (MPS), AbilityRelated Self-Talk (AST), Declaring Successful Self Control as a Goal (DSG), Highlighting Frame Conditions or Constraints (HFC), Highlighting Group Utility as a Goal (HGU), Emotional Contagion (ECG), Unspecific Motivational Regulation Strategies (UMS)

Resource oriented, non-motivational: Time Management and Coordination (TMC), Environmental Control (EC), Knowledge and Information Management (KIM), Attention Management (AM), Effort Management (EM), External Resource Management (ERM), Care of Social Atmosphere (CSA) 


\section{Results}

\section{Preliminary analyses}

In a first step, we checked whether our differentiation between coordination-related, motivational, and comprehension-related problems was plausible. CFAs that included the extent to which students experienced the 14 problems showed a superior model fit for the three-factor structure compared to other theoretically plausible one- or two-factor structures, $\left(\chi^{2}=\right.$ $\left.2965.899, p<.001, \chi^{2} / d f=32.59, \mathrm{CFI}=.89, \mathrm{RMSEA}=.07, \mathrm{SRMR}=.06\right)$. Note that the different problems in the list are considered to be primarily independent concepts, which would not make sense from a theoretical standpoint to be regressed on a latent factor. For example, having different goals is not causally related to having a different task understanding, though we classified them both as coordination-related problems. Thus, judging the degree of fit with typical standards for CFA would not be meaningful. However, we did perform the factor analysis for the purpose of determining which number of categories is best to group problems into for a more structured visualization. Also note that all other statistical procedures are based on actual problems (and strategies) only, not on problem categories.

In a second step, we computed the number of study meetings in which the learners reported experiencing each of the 14 problems as their most salient problem. In addition, we calculated to what extent participants selected immediate rather than non-immediate strategies to regulate these problems, and whether the use of immediate strategies was higher than would be expected by chance. The ratio of the choice of an immediate strategy in a particular problem situation compared to a random strategy choice in the same problem situation was expressed by a ratio value ' $R$ '. We also investigated to what extent the choice of immediate or nonimmediate strategies was linked to particular types of problems. This made it possible to identify interaction effects between the problem type and immediacy that could then be included in the subsequent hierarchical linear models.

Figure 2 shows how many participants who experienced a particular problem chose an immediate or non-immediate strategy to address that problem. For each single problem, the confidence intervals indicate that participants reported immediate strategies significantly more frequently than non-immediate strategies, with the exception of boring learning material. For this problem, the $95 \%$ confidence intervals for immediate strategies included the $50 \%$ mark, which can be seen as an indication that participants did not choose immediate strategies significantly more or less often than non-immediate strategies. In sum, for almost all problems, $61 \%$ to $90 \%$ of the answers included at least one immediate strategy. Percentages of immediate strategy use were particularly high for comprehension-related problems.

In addition, Fig. 2 includes the ratios 'R' of empirically observed immediate strategies by problem type compared to the random probability of choosing an immediate strategy for a particular problem. For coordination- and all comprehension-related problems, 'R's were $>1$. This indicates that when encountering coordination- and comprehension-related problems, participants typically reacted by selecting immediate strategies more often than non-immediate strategies, weighted by the probability for immediate strategies given the theoretical categorization (see Table 2). In contrast, the ratios of the three motivational problems were significantly $<1$, indicating that participants surprisingly selected more non-immediate than immediate strategies across problem types.

To determine the relations between our central predictor variables (the two homogeneity variables, immediacy of strategy use, and intensity of strategy use) and the satisfaction with the 


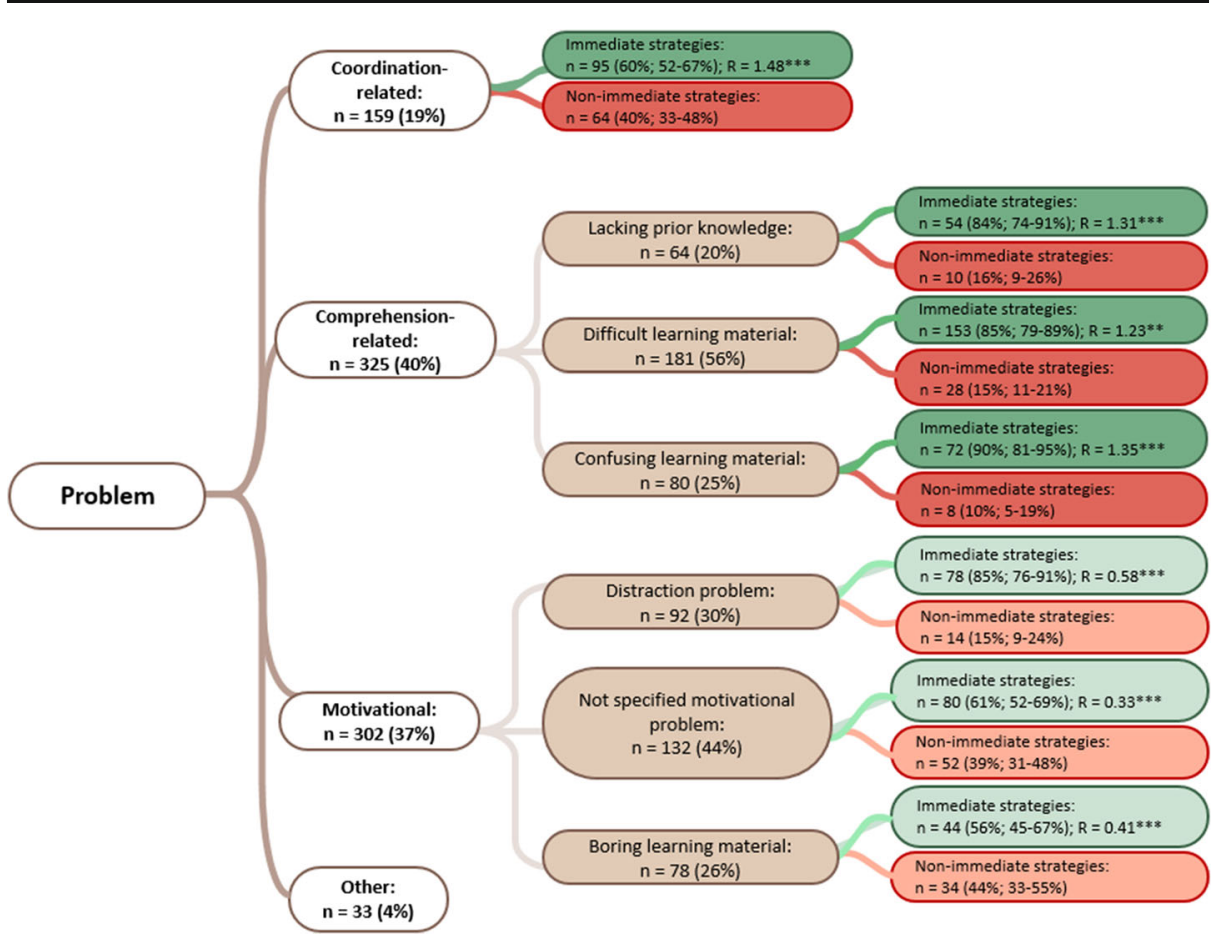

Fig. 2 Decision tree with absolute relative frequencies of problems and immediate vs. non-immediate strategy types (with $95 \%$ confidence intervals) and with ratios ' $\mathrm{R}$ '. $\dagger$ indicates $p \leq 0.1$, * indicates $p \leq .05$, ** indicates $p \leq .01, * * *$ indicates $p \leq .001$

group learning experience as a proximal outcome of the group learning process, we calculated bivariate correlations (see Table 3). Results showed that all predictors were significantly correlated with the satisfaction variable.

\section{Hierarchical linear models}

By calculating an unconditional means model (see Table 4), we tested whether there was variability in satisfaction with the group learning experience across individuals and groups. We found that there was no between-person variation regarding satisfaction with the group learning experience. Nevertheless, $24 \%$ of the variance in satisfaction was explained by the differing group means.

Table 3 Means, standard deviations, and correlations of the five variables

\begin{tabular}{lllllll}
\hline Variable & $M$ & $S D$ & 1 & 2 & 3 & 4 \\
\hline 1. Homogeneity (Problem type) & 0.72 & 0.40 & & & & \\
2. Homogeneity (Social level) & 0.43 & 0.49 & .06 & & & \\
3. Immediacy & 0.76 & 0.43 & .04 & -.09 & & $.17^{* *}$ \\
4. Intensity & 5.60 & 3.01 & $.09 *$ & -.05 & $.12^{* *}$ & $.19^{* * *}$ \\
5. Satisfaction & 4.92 & 1.32 & $.10^{*}$ & $.19^{* *}$ & & \\
\hline
\end{tabular}

$* p \leq .05, * * p \leq .01$ 
The second model, an unconditional growth model, was used to analyze whether satisfaction with the group learning experience was stable across meetings. First, the effect of the group level reported in the previous model remained significant (as in all subsequent models). In addition, we found a main effect of time $\left(\gamma_{100}\right)$ indicating that satisfaction with the group learning experience decreased over time.

The third model tested the relations between the two types of homogeneity of problem perceptions and satisfaction with the group learning experience. In line with Hypothesis $\mathrm{H}_{1}$, we found a positive correlation between homogeneity of problem perception with respect to problem type $\left(\gamma_{200}\right)$ as well as to social level $\left(\gamma_{300}\right)$ and satisfaction with the group learning experience. In both cases, satisfaction increased with increasing homogeneity. Thus, Hypothesis $\mathrm{H}_{1}$ was supported (see Fig. 3 Plot A and B).

The fourth model tested whether learners' satisfaction with the group learning experience was dependent on the immediacy of strategies they used to address their regulation problems $\left(\gamma_{400}\right)$. Based on the results of the preliminary analyses (Fig. 2), which indicated differential strategy preferences (immediate vs. other strategies) for different types of problems (coordination- and comprehension related problems vs. motivational problems), we added problem type $\left(\gamma_{500}\right)$ and the interaction of immediacy and problem type $\left(\gamma_{600}\right)$ to the model. First, we found a significant effect of immediacy on satisfaction with the group learning experience. Thus, Hypothesis $\mathrm{H}_{2}$ was supported. Further, we neither observed a significant main effect of the problem type nor a significant interaction effect of immediacy and problem type. In other words, we observed a positive effect of immediate strategy use on satisfaction with the group learning experience for the regulation, which was general across all types of problems (see Fig. 3 Plot C). Therefore, we dropped these exploratory terms in the subsequent model.

Finally, we tested the effect of intensity of strategy use on satisfaction with the group learning experience (Model 5). While all previously reported effects were stable, we also found a significant main effect of the intensity of strategy use $\left(\gamma_{700}\right)$ on satisfaction, as was predicted by Hypothesis $\mathrm{H}_{3}$. Thus, satisfaction with the group learning experience increased the more intensively students used regulation strategies (see Fig. 3 Plot D).

\section{Qualitative case analysis}

The quantitative analysis reported above indicates that learners were more satisfied the more homogeneous their problem perceptions were within their groups, the more immediate the strategies were they applied to cope with the most salient problem, and the more intensively they used strategies to remedy that problem. To illustrate how these effects might have been created, we also analyzed the open answers of two exemplary groups in a qualitative way. One of the two meetings (group 39) can be regarded as highly effective, whereas the other presents an example for a rather ineffective meeting (group 29).

The two learners from group 39 are displayed along with their documentation of the third study meeting. This group documented eight study meetings within 38 days during an exam phase. Thus, the dyad roughly met weekly. The study meetings consistently lasted about $1.5 \mathrm{~h}$. During each of these meetings, the group prepared for an oral exam in pedagogical anthropology. The satisfaction of this group across all meetings varied between 2 and $6(M=4.08$, $S D=1.04)$. The qualitative data of this group is presented in Table 5:

As can be seen in this table, the learners of group 39 show homogeneous problem perceptions of the type of problem perceived. In the subsequent questionnaire, they both reported homogeneously that they understood the task differently, and therefore consistently 
Table 4 Results of the multi-level models

\begin{tabular}{|c|c|c|c|c|c|c|c|c|c|}
\hline \multirow[b]{3}{*}{ Intercept $\gamma 000$} & Model 1 & Model 2 & \multicolumn{3}{|c|}{ Model 3} & \multirow{3}{*}{$\begin{array}{l}\text { Model } 4 \\
0.146\end{array}$} & \multicolumn{3}{|c|}{ Model 5} \\
\hline & \multicolumn{8}{|c|}{ Fixed Effects } & \\
\hline & $\begin{array}{l}0.03 \\
\quad(0.08)\end{array}$ & 0.19 & $(0.10)$ & 0.18 & $(0.01)$ & & $(0.10)$ & 0.14 & $(0.10)$ \\
\hline \multicolumn{10}{|l|}{ Level 1} \\
\hline Learning meeting $\gamma 100$ & & $-0.04 * *$ & $(0.01)$ & $-0.04 * *$ & $(0.01)$ & $-0.03 *$ & $(0.01)$ & $-0.03 *$ & $(0.01)$ \\
\hline Homog. Problem Type & & & & $0.11^{*}$ & $(0.04)$ & $0.11 *$ & $(0.04)$ & $0.09 *$ & $(0.04)$ \\
\hline$\gamma 200$ & & & & & & & & & \\
\hline Homog. Social Level $\gamma 300$ & & & & $0.15^{* * * *}$ & $(0.04)$ & $0.16 * * *$ & $(0.04)$ & $0.16 * * *$ & $(0.04)$ \\
\hline Immediacy $\gamma 400$ & & & & & & $0.10^{*}$ & $(0.04)$ & $0.08 *$ & $(0.05)$ \\
\hline Problem Type $\gamma 500$ & & & & & & -0.10 & $(0.04)$ & & \\
\hline Problem & & & & & & -0.07 & $(0.04)$ & & \\
\hline Type*Immediacy $\gamma 600$ & & & & & & & & & \\
\hline Intensity $\gamma 700$ & & & & & & & & $0.13 * *$ & $(0.04)$ \\
\hline \multicolumn{10}{|l|}{ Random Parameters } \\
\hline \multicolumn{10}{|l|}{ Level 2 (Persons) } \\
\hline Intercept $\operatorname{Var}(\Gamma 0)$ & 0.02 & 0.02 & & 0.02 & & 0.03 & & 0.04 & \\
\hline \multicolumn{10}{|l|}{ Level 3 (Groups) } \\
\hline Intercept $\operatorname{Var}\left({ }_{v 00}\right)$ & $0.24 * * *$ & $0.24 * * *$ & & $0.23 * * *$ & & $0.21 * * *$ & & $0.19 * *$ & \\
\hline \multicolumn{10}{|l|}{ Model Information } \\
\hline ICC (Persons) & 0.02 & 0.02 & & 0.03 & & 0.03 & & 0.05 & \\
\hline ICC (Groups) & 0.27 & 0.27 & & 0.28 & & 0.27 & & 0.26 & \\
\hline Observations & 489 & 489 & & 489 & & 489 & & 489 & \\
\hline $\begin{array}{l}\text { Marginal R2/Conditional } \\
\text { R2 }\end{array}$ & $0.00 / 0.27$ & $0.02 / 0.28$ & & $0.05 / 0.32$ & & $0.07 / 0.32$ & & $0.08 / 0.32$ & \\
\hline
\end{tabular}

rated their salient problem as a "coordination-related problem". The learners in this group also showed homogeneous problem perceptions regarding the social level of the most salient
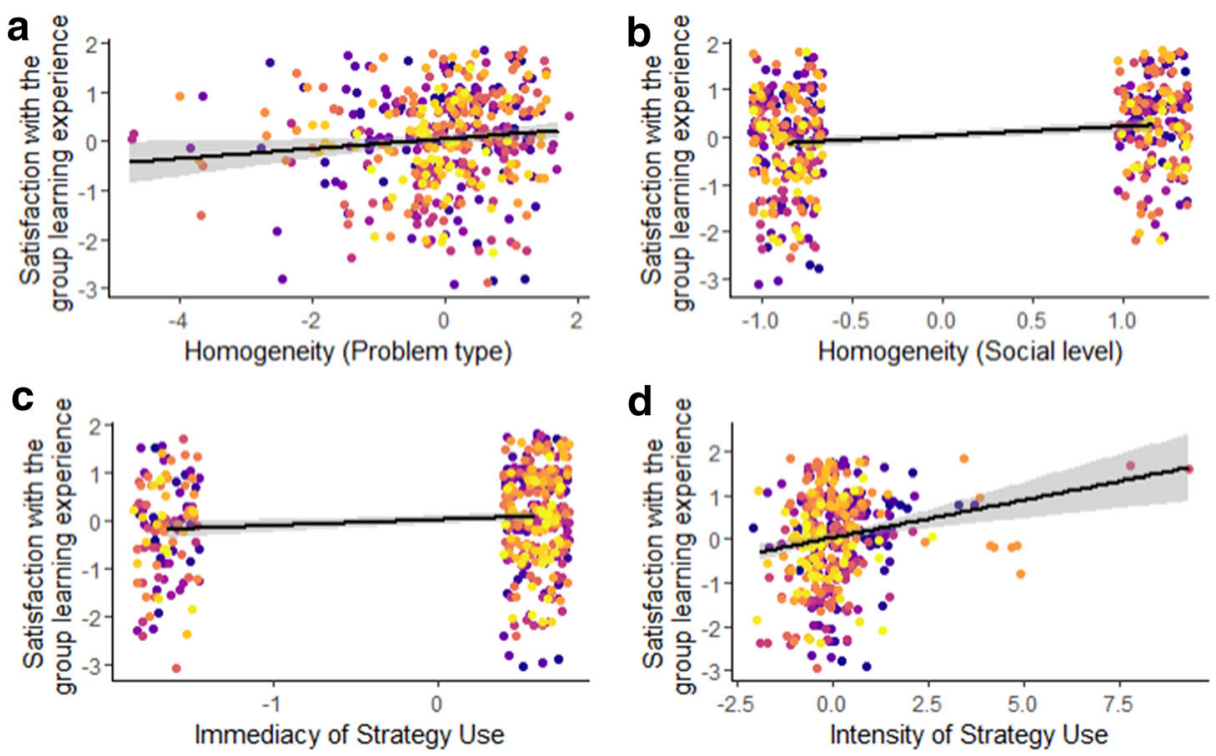

Fig. 3 Results of the homogeneity models (Plot A and B), the immediacy model (Plot C) and the intensity model (Plot D). Each dot represents one learner 
problem. After all, they mutually perceived the problem described as being equally "distributed" across the three social levels. In addition, both students show a high intensity of strategies they used: While learner 161 reported to have used eleven strategies to cope with the problem, learner 158 reported ten strategies compared to $M=5.6(S D=3.01)$ for the total sample. Regarding the immediacy of these strategies, both learners of the group exclusively used immediate strategies. Finally, both students reported they were satisfied with their study meeting. Accordingly, the reactions of this group for the study meeting show that both members successfully coordinated their metacognitive perceptions, their strategies, and their evaluations in the service of a co-constructed or shared outcome (Hadwin et al. 2011).

Further, the qualitative data of group 29 (fifth documented study meeting) is presented in Table 5. Almost all (except for the first) of the eleven documented meetings of this group took place within a 10 day period of time. These meetings usually lasted $2 \mathrm{~h}$, but the duration of the fifth meeting presented here lasted $5 \mathrm{~h}$. The group always studied in pairs, except for the tenth meeting, where they studied as a triad. The group prepared for various exams during the learning meetings. In the case of the meeting shown in Table 5, the group prepared for civil law and the law of obligation, while the other meetings all focused on criminal or public law. All of these exams were written exams. The satisfaction of this group across all meetings varied between 3 and $6(M=4.07, S D=1.1)$.

In contrast to group 39, learners in group 29 seem to have mastered their problems less well. The two students showed heterogeneous problem perceptions in relation to the type of problem: Learner 168 identified the most salient problem as a "coordination-related problem" because he perceived different goals within the group. This view, however, seemed not to be shared by learner 167 who categorized the most salient problem as a "comprehension-related problem". In the end, learner 167 noticed that both learners agreed as a group on a shared goal (probably while preparing for the earlier or more important exam), at the expense of their preparation for another exam. As can be seen from the table, the two learners in this group used relatively few strategies to overcome their most salient problem. While learner 168 used five strategies, his fellow learner only used three strategies. Furthermore, the two learners did not use any immediate strategies. In addition, the two learners indicated that they were rather dissatisfied with their study meeting. This reflects their less favorable characteristics on almost all of the variables employed in this study (with the exception of problem perception in relation to social levels). One might even question whether this group can rightly be considered to have engaged in collaborative learning at all (see Jeong et al. 2017).

\section{Discussion}

The majority of CSCL research so far has focused on how groups collaborate in formal contexts, often with an emphasis on how best to structure or "script" collaboration (e.g., de Wever et al. 2006). Yet, research on collaboration in informal settings, i.e., in situations during which learners deliberately form groups and then plan and execute their collaboration on their own, i.e., without external guidance, is scarce. More specifically, little is known about what makes self-organized collaboration a successful experience.

The few studies that exist in this field suggest that many groups experience comprehensionand coordination-related as well as motivational problems during collaboration, and that they often fail to effectively regulate these problems (Malmberg et al. 2015). As a result, group members often perceive their study meetings as unsatisfactory (Järvelä et al. 2010). The exact 
Table 5 Qualitative case examples of two selected groups

Problem Perception
Group 39: "hardworking learners"
Learner 161:
"We both understood the task
differently and therefore did not get
on the green track."

(goal: "For me personally repetition and start a new topic")

\section{Learner 158:}

"There were important terms that we had not understood in a similar way and it was difficult to come up with a meaningful answer."

(goal: "To develop and understand the material together and to keep the contents")

Group 29: "the kilics"

\section{Learner 168:}

"We had different goals."

(goal: To learn as much as possible for the exam)

\section{Learner 167:}

"We have focused on the more important exam and the other has moved into the background."

(goal: Tomorrow’s exam)
Strategy Use

Immediacy Satisfaction

Self: "I tried to communicate with my fellow student and find out what is the crux. of the matter. We both had a different idea of the task, so I tried to illuminate both sides to show her my point of view."

Co: "I tried to communicate with my fellow student and find out what is the crux of the matter. We both had a different idea of the task, so I tried to illuminate both sides to show her my point of view."

Shared: "We both went into each other and explained the task to each other."

Shared: "Everyone first expressed their idea, understanding of the term and then looked to see if there was any overlap. We also looked for explanations on the internet and in literature."

Co: "I tried not to cling too much to my opinion and to be willing to listen to other ideas and think them through and thus come up with an answer together."

Self: "I tried to be open to other opinions and opinions and thus to create links."

Self: "I let out my negative energy."

Co: "We tried not to distract each other. I tried to be quiet."

Shared: "We have thought that tomorrow is the exam.

Co: "I said that it was the last day before the exam, and everyone else didn't learn much, because the other exams are intermediate exams. I didn't say much about it, everything was aware to everyone."

Self: "I thought that I would get the most out of what I can learn in one day."

processes that account for a successful regulation of such problems have not been elucidated in prior work.

In this study, we assumed that successful self-organized collaborative learning depends on group members' abilities to develop homogeneous problem perceptions as well as on their respective abilities to use mainly immediate strategies at high levels of intensity. We therefore developed a theoretical model that differentiates between problem perception, strategy use and 
regulation effectivity (Fig. 1). In an ecologically valid setting, we investigated the association between four different possible predictors with students' satisfaction with their group learning experiences: (a) the homogeneity of group members' problem perception (both with respect to the type of problem and the social level at which the problem occurs; $R_{1}$ ), (b) the immediacy of the strategies students used $\left(\mathrm{RQ}_{2}\right)$ and $(\mathrm{c})$ the intensity of strategies they employed to regulate occurring problems $\left(\mathrm{RQ}_{3}\right)$.

Our results provide evidence that all proposed predictors are important for students' satisfaction with their group learning experiences. First, both variants of homogeneity regarding the perception of the type and the social level of the problem were positively associated with satisfaction with the group learning experience $\left(\mathrm{RQ}_{1}\right)$. According to our theoretical reasoning, homogeneous problem perception is likely to facilitate strategy employment, which in turn has the potential to make strategy use more effective and more in line with the group goals (Bolstad and Endsley 1999; Nelson and Cooprider 1996). To arrive at a high satisfaction with the group learning experience, we thus recommend that self-organized study groups try to work towards a homogeneous problem perception (both with respect to the type of problem and the social level at which it occurs) before employing any kind of cognitive strategy to interact with the learning material.

Second, the use of strategies that immediately address the present regulation problem (as compared to the use of non-immediate strategies) appears helpful for reaching higher levels of satisfaction with the group learning experience $\left(\mathrm{RQ}_{2}\right)$. Based on Zimmerman and Moylan (2009), we assumed that the choice of immediate strategies for the regulation of a particular problem should facilitate a more effective regulation of this problem and thus lead to greater satisfaction with the group learning experience. Though it seems that the problem type does interact with the selection of immediate strategies, this interaction did not predict satisfaction with the group learning experience. In other words: the choice of immediate strategies seems to be related to higher satisfaction with the group learning experience for any type of problem, whether it is coordination-related, motivational or comprehension-related.

In this context, one issue deserves further elaboration: In the absence of instruments that measure immediacy of strategy use, one challenge we faced was to arrive at a sound operationalization of this variable. Our approach was to map each strategy to different problems that we suspected could be addressed using that strategy. Our preliminary analyses seem to provide support for our mapping, at least for coordination- and comprehension-related problems: We found that for these types of problems, students apply significantly more immediate strategies than expected by chance. Thus, students seem to be sensitive to the types of problems they experience and design their regulation process in a way that orients towards these problems. This is in line with the assumption that during the performance phase, selfregulated learners engage in self-monitoring, which in turn facilitates the selection of appropriate strategies (e.g., Zimmerman and Moylan 2009).

However, this does not seem to be the case for motivational problems. There, we surprisingly found that students selected significantly fewer immediate strategies than expected by chance. This is in contrast with results of the study by Malmberg et al. (2015) who asked students of higher and lower performing groups in a collaborative learning phase what their most salient group problem was and how they regulated it. Results showed that both the higher and lower performing groups regulated motivation problems especially with motivational regulation strategies. The fact that our results do not confirm these findings indicates that the avoidance of immediate strategies when faced with motivational problems that we observed might actually reflect students' relative inability to effectively deal with motivational 
problems rather than indicate a suboptimal matching of regulation strategies to these types of problems. This interpretation is supported by the finding that the strategies we proposed to be immediate for regulating motivational problems were also connected to higher satisfaction with the group learning experience, while the selection of non-immediate strategies was connected to lower satisfaction.

Third, the intensity of strategy use also was a significant predictor of students' satisfaction with their group learning experience $\left(\mathrm{RQ}_{3}\right)$. Descriptively, this effect was even stronger than the effects of the other predictors. This result contradicts Zimmerman (2000) as well as Wirth and Leutner (2008) who argued that the use of immediate strategies should be more important for success than only the frequency of strategy use. On the other hand, our results show that the association between intensity and satisfaction with the group learning experience is still present when controlling for immediacy, which suggests that intensity of strategy use does play a role in successful regulation. For motivational regulation problems, this was also demonstrated by Eckerlein et al. (2019) who found a direct effect of the frequency of motivational regulation strategies on students' successful regulation of motivational problems in individual selfregulated learning. Further research is still needed to pinpoint the exact conditions under which the frequent use of a broad range of regulation strategies is of particular importance. For certain situations, especially ones in which groups experience problems for which they already have one or two effective strategies at their disposal, the selection of additional strategies might be superfluous. Given that our participants might frequently have found themselves in situations in which they did not have particularly strong strategies at their disposal (or in which they at least might not have been certain which strategies to apply), the selection and application of a broad range of strategies might nevertheless have been effective, at least with respect to leading to satisfaction with the group learning experience.

Our analysis of the two qualitative case examples further illustrated the theoretically hypothesized and empirically confirmed relationships between homogeneity of problem perception, immediacy and intensity of strategy use and satisfaction with the group learning experience. Furthermore, it also shed light on the assumed mechanism that links theses variables. As outlined in our theoretical model, holding homogeneous problem perceptions should be beneficial for subsequent choice and application of regulation strategies. The comparison of both case examples indicates that this might in fact be true: In the high performing group, both learners' regulatory engagement complemented and supported each others' efforts. In this group, it is possible to see how complementarity is achievable and achieved through the experience of homogeneous problem perceptions. In the low performing group, strategies were not complementary, likely because of heterogeneous problem perceptions, which might have hindered effective regulation, i.e., the choice of immediate strategies and their intensive application.

Overall, we argue that although our study was not conducted in a classical CSCL context (e.g., since we let the students choose whether or not to use technology to support their learning), we see high potential of our design and results to stimulate future CSCL research in multiple ways. First, our results suggest effective regulation of collaboration is associated with (a) arrival at homogeneous problem perceptions, (b) use of specific strategies that are immediate for solving the problems at hand, and (c) extensive use of regulation strategies. Yet, our own study as well as research by Malmberg et al. (2015) shows that many groups do not engage in these processes spontaneously. It is thus a delicate question how self-organized groups might be supported in developing homogeneous problem perceptions, selecting immediate strategies and exhibiting high regulation intensity. 
Proponents of research on scripting CSCL might argue that groups should be supported with rather detailed prompting regimes that distribute learning activities and roles among group members (Fischer et al. 2013). However, the very idea of a script could be seen in opposition to the ideal of a group engaging in self-organized collaboration. One might even invoke the concern over the danger of over-scripting collaboration (Dillenbourg 2002), though recent work challenges this concern (Radkowitsch et al. 2020). Nevertheless, self-organized groups might benefit from less coercive guidance, such as group awareness tools (Schnaubert and Bodemer 2019). Another option might be to improve skills for self-organized collaborative learning beforehand: Students could be trained, for example at the beginning of the semester, to increase awareness of different kinds of problems and to develop their abilities to diagnose them, to share their problem perception in the group in order to increase homogeneity of problem perception, to master a broad variety of regulation strategies (see Table 1), and to acquire strategic insight into which strategy is immediate and effective for which problem (see Table 2). Yet, more research is necessary to develop and test different ways for scaffolding self-organized study groups.

Second, we argue that the theoretical framework we presented in this article might lead CSCL research to explore new and formerly under-researched questions. For example, with respect to regulation processes, we only looked at the effects of homogeneity, immediacy and the intensity of strategy use. What we did not investigate is how learners arrive at a homogenous understanding of their problems, select immediate strategies, and apply them with sufficient intensity. Future CSCL research might investigate these processes, especially because knowledge about these processes might be very beneficial for designing precisely targeted scaffolds. Furthermore, there might even be more regulation processes that contribute to regulation effectivity: For example, regulation might be more effective when groups apply strategies they are able to produce at higher levels of quality. Also, more research is necessary to explore the mechanisms that are accountable for the relations we found between problem perceptions and regulation processes on the one hand and regulation effectivity on the other hand. For example, the more homogeneous the problem perceptions within groups are, the easier it might be to select immediate strategies. These conjectures have not yet been tested, and are therefore left for future research.

Third, we argue that our study shows that the differentiation between social levels of regulation during collaborative learning that was proposed by Järvelä and Hadwin (2013) is not only helpful for studying regulation processes, but also for investigating the effects of different problem perceptions that precede the actual regulation process. Furthermore, it might even be promising to apply the differentiation between the self-, co- and shared level to the concept of regulation efficacy, as group members may or may not arrive at similar levels of satisfaction (or other measures of regulation efficacy) as a result of the same collaboration experience.

\section{Limitations and conclusions}

Of course, this study is not without limitations: First, we heavily relied on self-report data, which has been regarded as less rigorous than other measurement approaches as it may suffer from low validity (see, for example, Berger and Karabenick 2016). Nevertheless, we felt that using self-report data was justified in this case because of our specific interest in satisfaction with the group learning. The experience of satisfaction is unquestionably subjective in nature, and effects on satisfaction might best be expressed in subjective rather than objective assessments. Theoretically, additional objective process data might have been obtained via event 
logs (Järvelä et al. 2019). However, we would have had to force learners to exclusively communicate via computer (for example, see Hadwin et al. 2018; Volet et al. 2009), which is contrary to the original intention to study collaborative learning in the naturalistic setting of self-organized study groups. Anecdotally, we noticed that groups mainly seemed to use computers as a knowledge repository and as an external resource, rather than as a means of communication. In future research, it might be interesting to look specifically at regulation processes of groups that used computers as a communication aid, compared to groups that did not. Second, as an outcome variable, we only included learners' satisfaction with their group learning experience as opposed to measuring learning or test preparedness. Of course, it would be interesting to see if there would be similar effects of the predictor variables on students' exam performance. In the context of our study, though, measuring objective performance data was not possible because participants prepared for different subjects such as mathematics, law, or teacher education, which were not known to us in advance. Thus, on the one hand, developing a single knowledge test for all participants was impossible, and on the other hand, the actual grades the participants achieved in the exams they were preparing for were not comparable due to the different subjects of study at different universities. Additionally, the actual exam grades would be difficult to causally associate with the regulation success in single study group meetings.

Third, it should be noted that some of our operationalizations might be questioned: We based our operationalization of immediacy of strategy use only on theoretical considerations (e.g., based on Eckerlein et al. 2019; Hadwin et al. 2018). Although future studies might employ a more differentiated coding of the immediacy variable, the fact that satisfaction increased with an increase in all our predictor variables while controlling for problem type actually supports our strategy-problem assignment. Additionally, because of the striking result that students seemed to neglect immediate strategies for motivational problems, future studies should investigate why students seem to regulate motivational problems primarily with nonimmediate strategies. Further, our operationalization of homogeneity regarding problem perception with respect to the social level at which the problem occurs may have been limited in cases in which the group consisted of more than two persons. Especially when students indicated that the problem was located at the co-level, measures did not reliably indicate whether or not the different group members attributed the problem to the same person(s). Also, intensity of strategy use was operationalized as frequency of any type of strategies. Instead, counting only particular strategies might have been an alternative option.

Last, we looked at the relations between the three constructs (1) homogeneity of problem perception, (2) immediacy and intensity of strategy use, and (3) satisfaction with the group learning experience at a global level only (though controlling for a linear trend of time and random differences between groups and persons). We did not investigate the dynamics of these variables and their interactions over time because of insufficient sample size, especially in the later meetings. This aspect of self-organized collaborative learning would be interesting to analyze in future research, especially given the recent discussion on the importance of temporality of learning processes in CSCL research (Molenaar and Järvelä 2014).

Despite these limitations, we believe that our study marks a promising starting point for future research on how self-organized study groups regulate their collaboration and how they might be scaffolded in this process. Especially in times of crisis, as during the current COVID19 pandemic, self-organized, technology-supported study groups might become even more frequent - a better understanding of this phenomenon should therefore be at the core of future CSCL research. 


\section{References}

Aggarwal, P., \& O’Brien, C. L. (2008). Social loafing on group projects. Journal of Marketing Education, 30(3), 255-264. https://doi.org/10.1177/0273475308322283.

Barron, B. (2003). When smart groups fail. Journal of the Learning Sciences, 12(3), 307-359. https://doi. org/10.1207/S15327809JLS1203_1.

Bates, D., Mächler, M., Bolker, B., \& Walker, S. (2015). Fitting linear mixed-effects models using lme4. Journal of Statistical Software, 67(1), 1-48. https://doi.org/10.18637/jss.v067.i01.

Berger, J.-L., \& Karabenick, S. A. (2016). Construct validity of self-reported metacognitive learning strategies. Educational Assessment, 21(1), 19-33. https://doi.org/10.1080/10627197.2015.1127751.

Bodemer, D., \& Dehler, J. (2011). Group awareness in CSCL environments. Computers in Human Behavior, 27(3), 1043-1045. https://doi.org/10.1016/j.chb.2010.07.014.

Bolstad, C. A., \& Endsley, M. R. (1999). Shared mental models and shared displays: An empirical evaluation of team performance. Proceedings of the Human Factors and Ergonomics Society Annual Meeting, 43(3), 213-217. https://doi.org/10.1177/154193129904300318.

de Wever, B., Schellens, T., Valcke, M., \& van Keer, H. (2006). Content analysis schemes to analyze transcripts of online asynchronous discussion groups: A review. Computers \& Education, 46(1), 6-28. https://oi. org/10.1016/j.compedu.2005.04.005.

Dillenbourg, P. (2002). Over-scripting CSCL: The risks of blending collaborativelearning with instructional design. In Kirschner, P. A., Jochems, W., Catherine, F. \& Magliozzi, R. (Eds.), Three worlds of CSCL. Can we support CSCL? (pp. 61-91). Open Universiteit Nederland.

Eckerlein, N., Roth, A., Engelschalk, T., Steuer, G., Schmitz, B., \& Dresel, M. (2019). The role of motivational regulation in exam preparation: Results from a standardized diary study. Frontiers in Psychology, $10,81$. https://doi.org/10.3389/fpsyg.2019.00081.

Engelschalk, T., Steuer, G., \& Dresel, M. (2015). Wie spezifisch regulieren Studierende ihre Motivation bei unterschiedlichen Anlässen? Zeitschrift für Entwicklungspsychologie und Pädagogische Psychologie, 47(1), 14-23. https://doi.org/10.1026/0049-8637/a000120.

Fischer, F., Kollar, I., Stegmann, K., \& Wecker, C. (2013). Toward a script theory of guidance in computersupported collaborative learning. Educational Psychologist, 48(1), 56-66. https://doi.org/10.1080 /00461520.2012.748005.

Friedrich, H. F., \& Mandl, H. (1992). Lern- und Denkstrategien - ein Problemaufriß. In H. F. Friedrich \& H. Mandl (Eds.), Lern- und Denkstrategien: Analyse und Intervention (pp. 3-54). Hogrefe.

Friedrich, H. F., \& Mandl, H. (2006). Lernstrategien: Zur Strukturierung des Forschungsfeldes. In H. Mandl \& H. F. Friedrich (Eds.), Handbuch Lernstrategien (1-23). Hogrefe.

Haake, J. M., \& Pfister, H.-R. (2010). Scripting a distance-learning university course: Do students benefit from net-based scripted collaboration? International Journal of Computer-Supported Collaborative Learning, 5(2), 191-210. https://doi.org/10.1007/s11412-010-9083-7.

Hadwin, A. F., Järvelä, S., \& Miller, M. (2011). Self-regulated, co-regulated, and socially shared regulation of learning. In B. J. Zimmerman \& D. H. Schunk (Eds.), Handbook of self-regulation of learning and performance (pp. 65-84). Routledge.

Hadwin, A. F., Bakhtiar, A., \& Miller, M. (2018). Challenges in online collaboration: Effects of scripting shared task perceptions. International Journal of Computer-Supported Collaborative Learning, 13(3), 301-329. https://doi.org/10.1007/s11412-018-9279-9.

Hurme, T.-R., \& Järvelä, S. (2005). Students' activity in computer-supported collaborative problem solving in mathematics. International Journal of Computers for Mathematical Learning, 10(1), 49-73. https://oi. org/10.1007/s10758-005-4579-3.

Hurme, T.-R., Palonen, T., \& Järvelä, S. (2006). Metacognition in joint discussions: An analysis of the patterns of interaction and the metacognitive content of the networked discussions in mathematics. Metacognition and Learning, 1(2), 181-200. https://doi.org/10.1007/s11409-006-9792-5.

Järvelä, S., \& Hadwin, A. F. (2013). New frontiers: Regulating learning in CSCL. Educational Psychologist, 48(1), 25-39. https://doi.org/10.1080/00461520.2012.748006.

Järvelä, S., \& Järvenoja, H. (2011). Socially constructed self-regulated learning and motivation regulation in collaborative learning groups. Teachers College Record, 113(2), 350-374.

Järvelä, S., Järvenoja, H., \& Veermans, M. (2008). Understanding the dynamics of motivation in socially shared learning. International Journal of Educational Research, 47(2), 122-135. https://doi.org/10.1016/j. ijer.2007.11.012.

Järvelä, S., Volet, S., \& Järvenoja, H. (2010). Research on motivation in collaborative learning: Moving beyond the cognitive-situative divide and combining individual and social processes. Educational Psychologist, 45(1), 15-27. https://doi.org/10.1080/00461520903433539. 
Järvelä, S., Järvenoja, H., Malmberg, J., \& Hadwin, A. F. (2013). Exploring socially shared regulation in the context of collaboration. Journal of Cognitive Education and Psychology, 12(3), 267-286. https://oi. org/10.1891/1945-8959.12.3.267.

Järvelä, S., Kirschner, P. A., Panadero, E., Malmberg, J., Phielix, C., Jaspers, J., Koivuniemi, M., \& Järvenoja, H. (2015). Enhancing socially shared regulation in collaborative learning groups: Designing for CSCL regulation tools. Educational Technology Research and Development, 63(1), 125-142. https://doi.org/10.1007 /s11423-014-9358-1.

Järvelä, S., Kirschner, P. A., Hadwin, A. F., Järvenoja, H., Malmberg, J., Miller, M., \& Laru, J. (2016). Socially shared regulation of learning in CSCL: Understanding and prompting individual- and group-level shared regulatory activities. International Journal of Computer-Supported Collaborative Learning, 11(3), 263-280. https://doi.org/10.1007/s11412-016-9238-2.

Järvelä, S., Hadwin, A., Malmberg, J., \& Miller, M. (2018). Contemporary perspectives of regulated learning in collaboration. International handbook of the learning sciences, 127-136.

Järvelä, S., Järvenoja, H., \& Malmberg, J. (2019). Capturing the dynamic and cyclical nature of regulation: Methodological Progress in understanding socially shared regulation in learning. International Journal of Computer-Supported Collaborative Learning, 14(4), 425-441. https://doi.org/10.1007/s11412-019-093132.

Järvenoja, H., \& Järvelä, S. (2005). How students describe the sources of their emotional and motivational experiences during the learning process: A qualitative approach. Learning and Instruction, 15(5), 465-480. https://doi.org/10.1016/j.learninstruc.2005.07.012.

Järvenoja, H., \& Järvelä, S. (2009). Emotion control in collaborative learning situations: Do students regulate emotions evoked by social challenges? British Journal of Educational Psychology, 79(3), 463-481. https://doi.org/10.1348/000709909X402811.

Järvenoja, H., Volet, S., \& Järvelä, S. (2013). Regulation of emotions in socially challenging learning situations: An instrument to measure the adaptive and social nature of the regulation process. Educational Psychology, 33(1), 31-58. https://doi.org/10.1080/01443410.2012.742334.

Järvenoja, H., Näykki, P., \& Törmänen, T. (2019). Emotional regulation in collaborative learning: When do higher education students activate group level regulation in the face of challenges? Studies in Higher Education, 44(10), 1747-1757. https://doi.org/10.1080/03075079.2019.1665318.

Jeong, H., Cress, U., Moskaliuk, J., \& Kimmerle, J. (2017). Joint interactions in large online knowledge communities: The A3C framework. International Journal of Computer-Supported Collaborative Learning, 12(2), 133-151. https://doi.org/10.1007/s11412-017-9256-8.

Kirschner, P. A., Beers, P. J., Boshuizen, H. P. A., \& Gijselaers, W. H. (2008). Coercing shared knowledge in collaborative learning environments. Computers in Human Behavior, 24(2), 403-420. https://doi. org/10.1016/j.chb.2007.01.028.

Koivuniemi, M., Panadero, E., Malmberg, J., \& Järvelä, S. (2017). Higher education students' learning challenges and regulatory skills in different learning situations. Infancia y Aprendizaje, 40(1), 159-185. https://doi.org/10.1080/02103702.2016.1272874.

Kollar, I., Fischer, F., \& Hesse, F. W. (2006). Kollaborationsskripte - eine konzeptionelle Analyse. Educational Psychology Review, 18(2), 19-55. https://doi.org/10.1007/s10648-006-9007-2.

Kuznetsova, A., Brockhoff, P. B., \& Christensen, R. H. B. (2017). lmerTest package: Tests in linear mixed effects models. Journal of Statistical Software, 82(13), 1-26. https://doi.org/10.18637/jss.v082.i13.

Leutner, D., Leopold, C., \& den Elzen-Rump, V. (2007). Self-regulated learning with a text-highlighting strategy. Journal of Psychology, 215(3), 174-182. https://doi.org/10.1027/0044-3409.215.3.174.

Malmberg, J., Järvelä, S., Järvenoja, H., \& Panadero, E. (2015). Promoting socially shared regulation of learning in CSCL: Progress of socially shared regulation among high- and low-performing groups. Computers in Human Behavior, 52, 562-572. https://doi.org/10.1016/j.chb.2015.03.082.

Miller, M., \& Hadwin, A. F. (2015). Scripting and awareness tools for regulating collaborative learning: Changing the landscape of support in CSCL. Computers in Human Behavior, 52, 573-588. https://oi. org/10.1016/j.chb.2015.01.050.

Molenaar, I., \& Järvelä, S. (2014). Sequential and temporal characteristics of self and socially regulated learning. Metacognition and Learning, 9(2), 75-85. https://doi.org/10.1007/s11409-014-9114-2.

Näykki, P., Järvelä, S., Kirschner, P. A., \& Järvenoja, H. (2014). Socio-emotional conflict in collaborative learning - a process-oriented case study in a higher education context. International Journal of Educational Research, 68, 1-14. https://doi.org/10.1016/j.ijer.2014.07.001.

Näykki, P., Isohätälä, J., Järvelä, S., Pöysä-Tarhonen, J., \& Häkkinen, P. (2017). Facilitating socio-cognitive and socio-emotional monitoring in collaborative learning with a regulation macro script-An exploratory study. International Journal of Computer-Supported Collaborative Learning, 12(3), 251-279. https://doi. org/10.1007/s1 1412-017-9259-5. 
Neber, H. (2006). Fragenstellen. In H. Mandl \& H. F. Friedrich (Eds.), Handbuch Lernstrategien (pp. 50-58). Hogrefe.

Nelson, K. M., \& Cooprider, J. G. (1996). The contribution of shared knowledge to IS group performance. MIS Quarterly, 20(4), 409-432. https://doi.org/10.2307/249562.

Noroozi, O., Bayat, A., \& Hatami, J. (2019). Effects of a digital guided peer feedback system on student learning and satisfaction. In K. Lund, G. P. Niccolai, E. Lavoué, C. E. Hmelo-Silver, G. Gweon, \& M. Baker (Eds.), A wide lens: Combining embodied, enactive, extended, and embedded learning in collaborative settings. Proceedings of the 13th international conference on computer-supported collaborative learning (CSCL) 2019, (Vol. 2. pp. 809-810). Lyon: International Society of the Learning Sciences.

Popov, V., van Leeuwen, A., \& Buis, S. C. A. (2017). Are you with me or not? Temporal synchronicity and transactivity during CSCL. Journal of Computer Assisted Learning, 1-19. https://doi.org/10.1111 /jcal.12185.

R Development Core Team. (2018). R: A language and environment for statistical compu-ting (Version 3.5.2) [Computer software]. https://www.r-project.org

Radkowitsch, A., Vogel, F., \& Fischer, F. (2020). Good for learning, bad for motivation? A meta-analysis on the effects of computer-supported collaboration scripts. International Journal of Computer-Supported Collaborative Learning, 15(1), 5-47.

Raes, A., Schellens, T., De Wever, B., \& Benoit, D. F. (2016). Promoting metacognitive regulation through collaborative problem solving on the web: When scripting does not work. Computers in Human Behavior, $58,325-342$.

Rummel, N., Spada, H., \& Hauser, S. (2009). Learning to collaborate from being scripted or from observing a model. International Journal of Computer-Supported Collaborative Learning, 4(1), 69-92.

Sansone, C., \& Thoman, D. B. (2005). Interest as the missing motivator in self-regulation. European Psychologist, 10(3), 175-186. https://doi.org/10.1027/1016-9040.10.3.175.

Schnaubert, L., \& Bodemer, D. (2019). Providing different types of group awareness information to guide collaborative learning. International Journal of Computer-Supported Collaborative Learning, 14(1), 7-51. https://doi.org/10.1007/s11412-018-9293-y.

Schoor, C., \& Bannert, M. (2012). Exploring regulatory processes during a computer-supported collaborative learning task using process mining. Computers in Human Behavior, 28(4), 1321-1331. https://doi. org/10.1016/j.chb.2012.02.016.

Schwinger, M., \& Otterpohl, N. (2017). Which one works best? Considering the relative importance of motivational regulation strategies. Learning and Individual Differences, 53, 122-132. https://doi. org/10.1016/j.lindif.2016.12.003.

Schwinger, M., Steinmayr, R., \& Spinath, B. (2009). How do motivational regulation strategies affect achievement: Mediated by effort management and moderated by intelligence. Learning and Individual Differences, 19(4), 621-627. https://doi.org/10.1016/j.lindif.2009.08.006.

Singer, J. D., \& Willett, J. B. (2003). Applied longitudinal data analysis: Modeling change and event occurrence. Oxford University Press.

Splichal, J. M., Oshima, J., \& Oshima, R. (2018). Regulation of collaboration in project-based learning mediated by CSCL scripting reflection. Computers \& Education, 125, 132-145. https://doi.org/10.1016/j. compedu.2018.06.003.

Stahl, G. (2015). Conceptualizing the intersubjective group. International Journal of Computer-Supported Collaborative Learning, 10(3), 209-217. https://doi.org/10.1007/s11412-015-9220-4.

Vauras, M., Iiskala, T., Kajamies, A., Kinnunen, R., \& Lehtinen, E. (2003). Shared-regulation and motivation of collaborating peers: A case analysis. Psychologia: An International Journal of Psychology in the Orient, 46(1), 19-37. https://doi.org/10.2117/psysoc.2003.19.

Vogel, F., Wecker, C., Kollar, I., \& Fischer, F. (2017). Socio-cognitive scaffolding with computer-supported collaboration scripts: A meta-analysis. Educational Psychology Review, 29(3), 477-511. https://doi. org/10.1007/s10648-016-9361-7.

Volet, S., Summers, M., \& Thurman, J. (2009). High-level co-regulation in collaborative learning: How does it emerge and how is it sustained? Learning and Instruction, 19(2), 128-143. https://doi.org/10.1016/j. learninstruc.2008.03.001.

Vollmeyer, R. (2006). Ansatzpunkte für die Beeinflussung von Lernmotivation. In H. Mandl \& H. F. Friedrich (Eds.), Handbuch Lernstrategien (pp. 223-231). Hogrefe.

Wecker, C., \& Fischer, F. (2014). Lernen in Gruppen. In T. Seidel \& A. Krapp (Eds.), Pädagogische Psychologie (6th ed., pp. 277-296). Beltz.

Winne, P. H., \& Hadwin, A. F. (1998). Studying as self-regulated learning. In D. J. Hacker, J. Dunlosky, \& A. C. Graesser (Eds.), Metacognition in educational theory and practice (277-304). Routledge.

Wirth, J., \& Leutner, D. (2008). Self-regulated learning as a competence. Zeitschrift für Psychologie, 216(2), 102-110. https://doi.org/10.1027/0044-3409.216.2.102. 
Zheng, L., Li, X., \& Huang, R. (2017). The effect of socially shared regulation approach on learning performance in computer-supported collaborative learning. Journal of Educational Technology \& Society, 20(4), 35-46.

Zimmerman, B. J. (2000). Self-efficacy: An essential motive to learn. Contemporary Educational Psychology, 25(1), 82-91. https://doi.org/10.1006/ceps.1999.1016.

Zimmerman, B. J., \& Moylan, A. R. (2009). Self-regulation: Where metacognition and motivation intersect. In D. J. Hacker, J. Dunlosky, \& A. C. Graesser (Eds.), Handbook of metacognition in education (pp. 299-315). Routledge.

Publisher's note Springer Nature remains neutral with regard to jurisdictional claims in published maps and institutional affiliations.

\title{
Affiliations
}

\section{Nadine Melzner ${ }^{1} \cdot$ Martin Greisel $^{2} \cdot$ Markus Dresel $^{2} \cdot$ Ingo Kollar $^{2}$}

\author{
Martin Greisel \\ martin.greisel@phil.uni-augsburg.de \\ Markus Dresel \\ markus.dresel@phil.uni-augsburg.de \\ Ingo Kollar \\ ingo.kollar@phil.uni-augsburg.de
}

1 Susanne Klatten Endowed Chair for Teaching and Learning with Digital Media, Technical University of Munich, Marsstraße 20, 80335 Munich, Germany

2 Faculty of Philosophy and Social Sciences, University of Augsburg, Universitätsstraße 10, 86135 Augsburg, Germany 